medRxiv preprint doi: https://doi.org/10.1101/2020.05.23.20110528; this version posted May 26,2020 . The copyright holder for this preprint (which was not certified by peer review) is the author/funder, who has granted medRxiv a license to display the preprint in perpetuity. All rights reserved. No reuse allowed without permission.

\title{
Protocol for a retrospective, comparative effectiveness study of the association between transesophageal echocardiography (TEE) monitoring used in coronary artery bypass graft (CABG) surgery and clinical outcomes
}

\author{
Emily J. Mackay ${ }^{1,}$, Bo Zhang ${ }^{2}$, Siyu Heng ${ }^{3}$, and Ting Ye ${ }^{2}$ \\ ${ }^{1}$ Department of Anesthesiology and Critical Care, Perelman School of Medicine, University of \\ Pennsylvania, Philadelphia, PA, U.S.A. \\ ${ }^{2}$ Department of Statistics, The Wharton School, University of Pennsylvania, Philadelphia, \\ PA, U.S.A. \\ ${ }^{3}$ Graduate Group in Applied Mathematics and Computational Science, School of Arts and \\ Sciences, University of Pennsylvania, Philadelphia, PA, U.S.A.
}

\begin{abstract}
Background: Coronary artery bypass graft (CABG) surgery is the most widely performed adult cardiac surgery in the US. Transesophageal echocardiography (TEE) is an ultrasound-based cardiac imaging modality used in CABG surgery for hemodynamic monitoring and management of complications related to cardiopulmonary bypass. However, there are no comparative effectiveness studies (randomized or non-randomized) that have investigated the relationship between TEE monitoring and clinical outcomes among patients undergoing CABG surgery. Because of this lack of evidence, recommendations for TEE in CABG surgery remain indeterminate (Class II). We aim to compare the clinical outcomes of patients undergoing CABG surgery with vs without TEE monitoring. This protocol will detail how we plan to investigate the hypothesis that TEE monitoring in CABG surgery will be associated with improved clinical outcomes.

Methods and Analysis: This investigation will be an observational retrospective, comparative effectiveness, cohort study using Centers for Medicare and Medicaid Services (CMS) claims data from January 1, 2013 to October 15, 2015. The aim is to determine if TEE monitoring during CABG surgery is associated with improved 30-day survival, lower incidence of stroke, shorter length of hospitalization, and incidence of esophageal perforation. To alleviate the potential bias from unmeasured confounding, we propose leveraging hospitals' (or surgeons') preference for TEE in CABG surgery as an instrumental variable (IV). We will combine this IV technique with statisticalmatching-based methods by pairing hospitals (or surgeons) with similar observed confounding variables but considerably different preference for TEE monitoring in CABG surgery. Our research design is meant to emulate a cluster-randomized encouragement experiment. The following a priori protocol will detail how we plan to execute this analysis.
\end{abstract}

\section{Background and motivation}

Coronary artery bypass graft (CABG) surgery is the most widely performed adult cardiac surgery, accounting for over half of the 300,000 cardiac surgeries performed in the US each year (The Society of Thoracic Surgeons, 2016b). While CABG surgery carries a lower risk of death (2\%) (Jacobs et al., 2018), compared to that of valve surgery (5\%) (Smith et al., 2011, Acker et al., 2014, Reardon et al., 2017), the decline in CABG surgery by the expansion of percutaneous coronary revascularization (Epstein et al., 2011, Riley et al., 2011, The Society of Thoracic Surgeons, 2016a) means that patients who do require CABG surgery are increasingly sicker, have a higher coronary artery disease burden, and higher rates of comorbid conditions (Aldea et al., 2009, Mokadam et al., 2011, Cao et al., 2013,

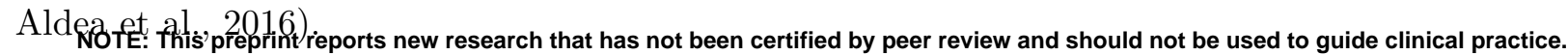

* Address for Correspondence: Emily J. Mackay, Department of Anesthesiology and Critical Care, Perelman School of Medicine, University of Pennsylvania, Philadelphia, PA, U.S.A. (E-mail: emily.mackay@pennmedicine.upenn.edu). 
medRxiv preprint doi: https://doi.org/10.1101/2020.05.23.20110528; this version posted May 26,2020 . The copyright holder for this preprint (which was not certified by peer review) is the author/funder, who has granted medRxiv a license to display the preprint in perpetuity.

All rights reserved. No reuse allowed without permission.

Transesophageal echocardiography (TEE) is an ultrasound-based, cardiac imaging modality, frequently used in CABG surgery for hemodynamic monitoring and management of complications related to cardiopulmonary bypass (Cheung et al., 1994, Shapira et al., 2004, Charron et al., 2006, Shapira et al., 2007, Eltzschig et al., 2008, Silva et al., 2010, Hahn et al., 2013, Nishimura et al., 2014, 2017). While complications directly related to TEE are rare (Hilberath et al., 2010), unnecessary procedures performed for incidental findings diagnosed by TEE during CABG surgery has been associated with worse clinical outcomes (Krasuski et al., 2009), and guidelines for TEE monitoring in CABG surgery remain indeterminate (Hahn et al., 2013, Hillis et al., 2011). Nevertheless, because of its ability to accurately differentiate between cardiac failure and hypovolemia (Cheung et al., 1994, Charron et al., 2006, Eltzschig et al., 2008, Silva et al., 2010, Hahn et al., 2013, Nishimura et al., 2014, 2017), routine perioperative monitoring with TEE could potentially improve clinical outcomes if it led to better hemodynamic management during CABG surgery.

So far, there are no randomized comparative effectiveness studies investigating the relationship between TEE monitoring and clinical outcomes among patients undergoing isolated CABG surgery. Observational work from our group has demonstrated that the use of TEE in CABG surgery is highly variable, ranging from $11 \%$ to $91 \%$ across US states (MacKay et al., 2020). Such variability in the practice of TEE for CABG surgery presents a comparative effectiveness research opportunity to evaluate the impact of TEE use on perioperative outcomes of CABG surgery patients.

\section{Overview of the research design}

We plan to undertake an observational retrospective, comparative effectiveness, cohort study using Centers for Medicare and Medicaid (CMS) claims data from January 1st, 2013 to October 15th, 2015 to determine if TEE monitoring during CABG surgery was associated with 30-day mortality (primary outcome), length of hospitalization (secondary outcome), incidence of stroke (secondary outcome), and incidence of esophageal perforation (secondary outcome).

We anticipated that sicker patients would be more likely to receive perioperative TEE for CABG surgery. Therefore, a direct comparison between patients receiving TEE monitoring and those not receiving TEE monitoring is not warranted. Controlling for observed confounding variables helps eliminate some of the selection bias; however, bias from factors that are not measured or accounted for, e.g., patients' ejection fraction, hemodynamics including blood pressure, cardiac index, and use of inotropic or vasopressor medications in operating room, and laboratory values, would remain.

To alleviate the potential bias from aforementioned unmeasured confounding variables, we propose to leverage hospitals' (or surgeons') preference for using TEE during CABG surgery as an instrumental variable. Classical approaches to preference-based-IV analyses typically rely on structural equation models or other parametrized models to control for IV-outcome confounders (Brookhart et al., 2006, Hernán and Robins, 2006). Examples include the two-stage-least-squares (2SLS) method and variants of it. Despite their convenience and simplicity, these parametric models rely on model assumptions that are often difficult to check. Statistical-matching-based methods, on the other hand, provide a tempting nonparametric alternative to structural equation models. We propose to apply a matchingbased approach to the current study. In particular, we pair hospitals (or surgeons) with similar confounding variables but considerably different preference for TEE monitoring in CABG surgery. Our research design is meant to replicate a cluster-randomized encouragement experiment (also known as a cluster-randomized experiment with individual noncompliance) (Frangakis et al., 2002, Small et al., 2008). More details on statistical matching and inference in the context of preference-based IV analyses are discussed in detail in Zhang et al. [2020] and sketched in Section 6.

\section{$3 \quad$ Eligibility and exclusion criteria}

We consider the following eligibility and exclusion criteria that lead to the final study cohort. Number of subjects left in the study after applying each exclusion criterion is indicated in the parentheses.

1. Identify all non-duplicate beneficiaries undergoing isolated CABG, i.e. any case with an ICD-9 code for CABG surgery $(\mathrm{n}=530,769)$; 
medRxiv preprint doi: https://doi.org/10.1101/2020.05.23.20110528; this version posted May 26, 2020. The copyright holder for this preprint (which was not certified by peer review) is the author/funder, who has granted medRxiv a license to display the preprint in perpetuity.

All rights reserved. No reuse allowed without permission.

2. Exclude beneficiaries in managed care (MC) and therefore without Part B claims $(\mathrm{n}=406,588)$;

3. Exclude beneficiaries without at least six months of coverage prior to index admission $(\mathrm{n}=$ $380,041)$

4. Exclude beneficiaries younger than 65 years of age $(\mathrm{n}=344,009)$;

5. Exclude beneficiaries without a cardiac surgery related DRG code $(\mathrm{n}=342,368)$;

6. Exclude years prior to $2013(\mathrm{n}=117,519)$;

7. Exclude beneficiaries who had a stroke diagnosis within the six months prior to index admission for cardiac surgery and those who had a stroke that was "present on admission" (POA), and therefore not a complication post-cardiac surgery $(\mathrm{n}=114,871)$;

8. When analyzing data at a surgeon-level granularity, we further exclude beneficiaries without a CPT code for CT surgery $(\mathrm{n}=101,522)$.

TEE billing information is coded on CPT codes found in Part B claims. Step 2 excludes beneficiaries in managed care, who enrolled in fee-for-service, and therefore were without Part B, physician billing claims. Step 4 excludes beneficiaries enrolled in Medicare for disability or for end-stage renal disease. Step 5 excludes atypical beneficiaries of the procedure or had procedural miscoding.

\section{Instrumental variable and IV-outcome confouders}

We propose to leverage hospitals' (or surgeons') preference as an instrumental variable for patients' receiving TEE monitoring during CABG surgery. We calculate the fraction of TEE usage out of CABG surgeries in our cohort for each hospital (or surgeon), and use this fraction as a measure of hospitals' (or surgeons') preference. Hospitals' (or surgeons') preference is identical for all patients treated in the same hospital (or by the same surgeon) and thus is a cluster-level IV. Importantly, although the IV is identical for different units within each cluster, there is individual noncompliance, i.e., each individual patient may or may not actually receive TEE monitoring during his/her CABG surgery.

An ideal instrumental variable has its variation completely exogenous; for instance, this is the case if draft lottery is used as an IV. In the context of observational studies, the results of an IV analysis may be biased if the IV and outcome are related by the so-called "instrument-outcome confounders" (Garabedian et al., 2014). In particular, Garabedian et al. [2014] pointed out the following potential instrument-outcome confounders: patients' race, socioeconomic status, clinical risk factors, health status, facility and procedure volume, etc. Hospitals' (or surgeons') preference is more likely to be a valid instrumental variable after controlling for these IV-outcome confounding variables. We follow advice in Garabedian et al. [2014] and control for these IV-outcome confounding variables in our study.

Specifically, we control for two types of IV-outcome confounding variables: 1) unit-level confounding variables and 2) cluster-level confounding variables. Unit-level confounding variables refer to those related to each patient in the cluster and include the following:

- age;

- gender;

- race (white or not);

- nature of the surgery (elective or not),

and the following seven comorbid conditions:

- arrhythmia;

- congestive heart failure;

- diabetes;

- hypertension; 
medRxiv preprint doi: https://doi.org/10.1101/2020.05.23.20110528; this version posted May 26, 2020. The copyright holder for this preprint (which was not certified by peer review) is the author/funder, who has granted medRxiv a license to display the preprint in perpetuity.

- obesity;

- pulmonary diseases;

- renal diseases.

We will further assume that hospitals' (or surgeons') preference and patients' clinical outcomes are confounded by above confounding variables via some aggregate measures, e.g., the average age of patients in the cluster, percentage of patients who are male, percentage of patients with arrhythmia, etc.

Cluster-level confounding variables refer to characteristics related to each hospital (or surgeon), and include the following:

- total number of hospital beds;

- total number of full-time registered nurses;

- whether or not the hospital is a teaching hospital;

- whether or not the hospital is equipped with a cardiac intensive care unit;

- total cardiac surgery volume between January 1st, 2013 and October 15th, 2015 of the hospital (or the surgeon).

These cluster-level covariates are obtained from the American Hospital Association and merged to the patient-level Medicare and Medicaid claims data using organization/surgeon identifier numbers.

Left panel of Figure 1 plots the standardized differences for these covariates when comparing hospitals with IV (TEE usage preference) above the median and those below the median. Right panel of Figure 1 plots the same information at the surgeon level. Figure 1a suggests that hospitals that have a strong preference for TEE usage tend to have more hospital beds, more full-time registered nurses, larger surgical volume, and are more likely to be teaching hospitals. Patients in hospitals with larger preference for TEE usage also tend to be older, and more often have preexisting comorbid conditions including arrhythmia, pulmonary, and renal diseases. We saw a similar trend at the surgeon level.

\section{$5 \quad$ Data granularity and outcomes}

\subsection{Data granularity}

We will match the data at two different granularities: 1) hospital level and 2) surgeon level. Each hospital (or surgeon) defines a natural cluster of patients, i.e., those treated in the hospital or by the surgeon. We identified which patients belong to the same cluster (hospital or surgeon) using National Provider Identifier (NPI) numbers available in the CMS claims data. We will evaluate the quality of the match, including covariate balance, sample size, and difference in the encouragement dosage, and determine a granularity at which the primary analysis is carried out. The other granularity will be analyzed in a sensitivity analysis.

\subsection{Primary outcomes}

We consider one primary outcome: 30-day mortality.

\subsection{Secondary outcomes}

We consider three secondary outcomes:

1. 30-day mortality or incidence of stroke;

2. Length of hospitalization;

3. Incidence of esophageal perforation. 
medRxiv preprint doi: https://doi.org/10.1101/2020.05.23.20110528; this version posted May 26, 2020. The copyright holder for this preprint (which was not certified by peer review) is the author/funder, who has granted medRxiv a license to display the preprint in perpetuity.

All rights reserved. No reuse allowed without permission.

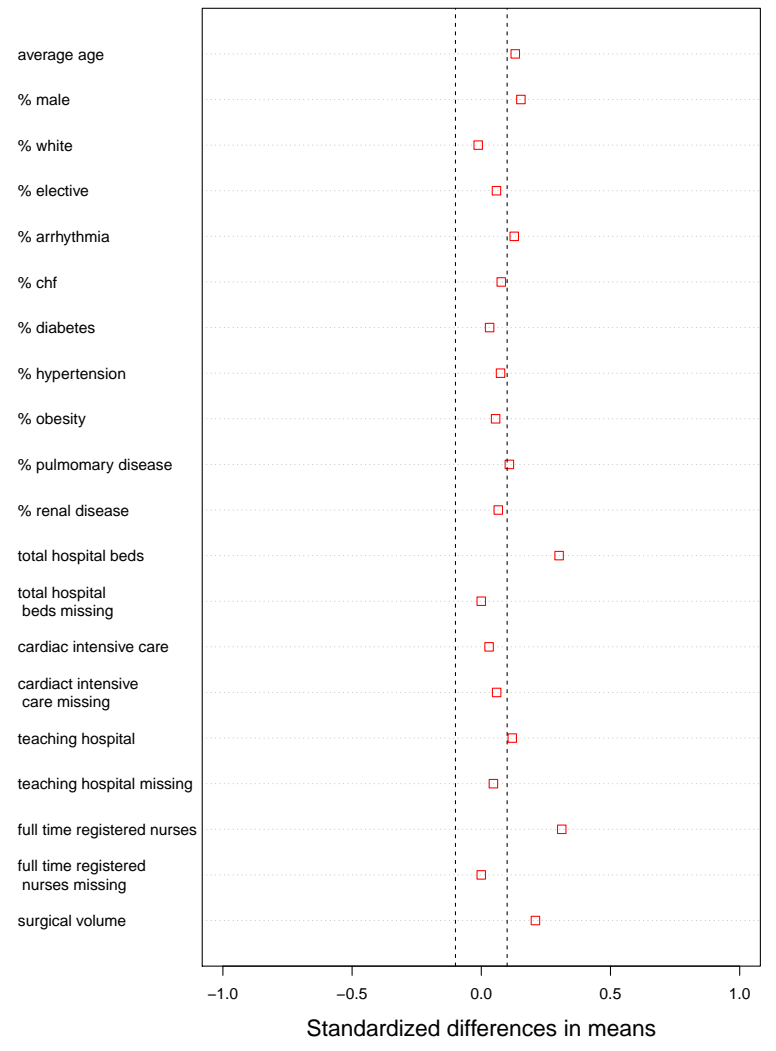

(a) Hospital level

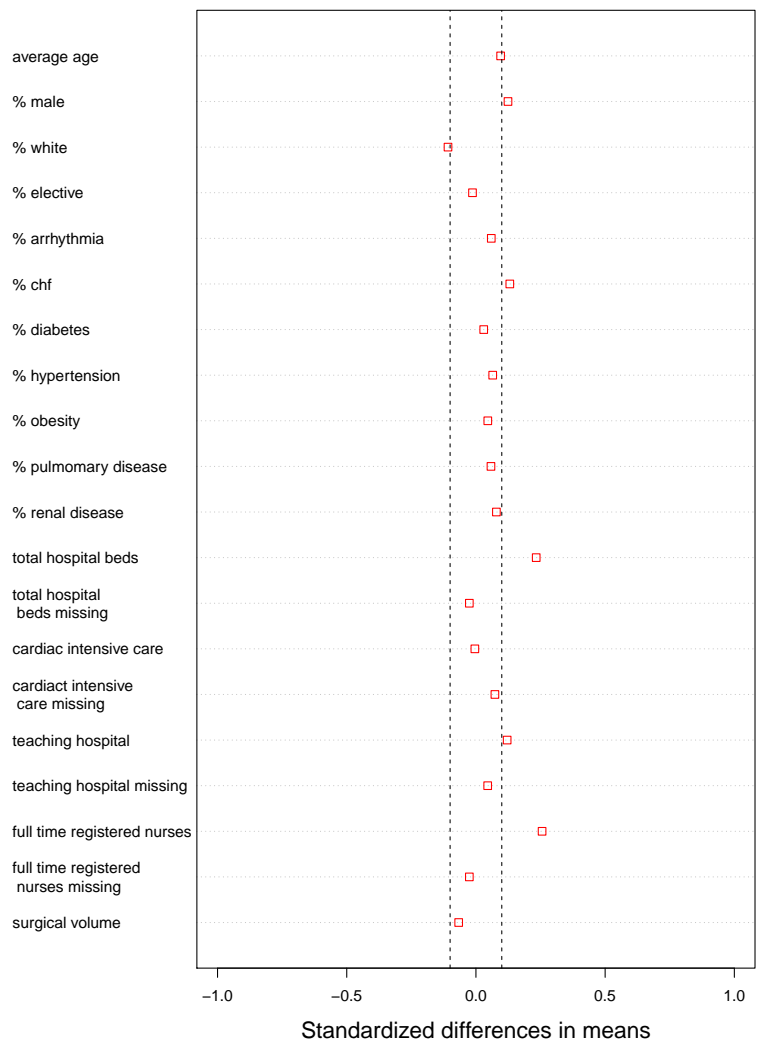

(b) Surgeon level

Figure 1: Love plot of standardized differences before matching. The standardized difference is calculated as (covariate mean of hospitals with IV above the median - covariate mean of hospitals with IV below the median) divided by the pooled within group standard deviation. Dashed lines are at -0.1 and 0.1 standardized differences. 
medRxiv preprint doi: https://doi.org/10.1101/2020.05.23.20110528; this version posted May 26,2020 . The copyright holder for this preprint (which was not certified by peer review) is the author/funder, who has granted medRxiv a license to display the preprint in perpetuity.

All rights reserved. No reuse allowed without permission.

Table 1: Covariate balance before matching. We compare hospitals (or surgeons) with TEE preference above the median to those with TEE preference below the median. Significance codes: “*” 0.05; “**" $0.01 ;$ “***" 0.001 .

\begin{tabular}{|c|c|c|c|c|c|c|}
\hline & \multicolumn{3}{|c|}{ Hospital level } & \multicolumn{3}{|c|}{ Surgeon level } \\
\hline & Below & Above & Standardized & Below & Above & Standardized \\
\hline & Median & Median & Difference & Median & Median & Difference \\
\hline $\begin{array}{l}\text { Instrumental variable: proportion } \\
\text { of TEE used in CABG surgeries }\end{array}$ & 0.27 & 0.81 & 3.61 & 0.39 & 0.95 & 3.09 \\
\hline \multicolumn{7}{|l|}{ Patient-level Characteristics } \\
\hline Average age & 75.10 & 75.33 & $0.13^{*}$ & 75.25 & 75.53 & $0.10^{* * *}$ \\
\hline$\%$ male & 0.67 & 0.69 & $0.15^{* *}$ & 0.68 & 0.70 & $0.12^{* * *}$ \\
\hline$\%$ white & 0.85 & 0.85 & -0.01 & 0.88 & 0.86 & $-0.11^{* * *}$ \\
\hline$\%$ elective & 0.46 & 0.47 & 0.06 & 0.48 & 0.47 & -0.01 \\
\hline$\%$ with arrhythmia & 0.10 & 0.11 & $0.13^{*}$ & 0.11 & 0.12 & $0.06^{*}$ \\
\hline$\%$ with congestive heart failure & 0.11 & 0.11 & 0.08 & 0.10 & 0.12 & $0.13^{* * *}$ \\
\hline$\%$ with diabetes & 0.16 & 0.16 & 0.03 & 0.16 & 0.16 & 0.03 \\
\hline$\%$ with hypertension & 0.27 & 0.28 & 0.07 & 0.28 & 0.30 & $0.06^{*}$ \\
\hline$\%$ with obesity & 0.05 & 0.06 & 0.06 & 0.06 & 0.06 & 0.05 \\
\hline$\%$ with pulmonary diseases & 0.02 & 0.02 & 0.11 & 0.02 & 0.02 & $0.06^{*}$ \\
\hline$\%$ with renal diseases & 0.08 & 0.09 & 0.07 & 0.08 & 0.10 & $0.08^{* *}$ \\
\hline \multicolumn{7}{|l|}{ Cluster-level Characteristics } \\
\hline Hospital beds & 340.79 & 415.81 & $0.30^{* * *}$ & 449.83 & 521.65 & $0.23^{* * *}$ \\
\hline Hospital beds (missing) & 0.01 & 0.01 & 0.00 & 0.01 & 0.01 & -0.03 \\
\hline Cardiac ICU (yes/no) & 0.71 & 0.72 & 0.03 & 0.83 & 0.83 & 0.00 \\
\hline Cardiac ICU (missing) & 0.07 & 0.09 & 0.06 & 0.04 & 0.05 & $0.07^{* *}$ \\
\hline Teaching hospital & 0.15 & 0.20 & $0.12^{*}$ & 0.27 & 0.33 & $0.12^{* * *}$ \\
\hline Teaching hospital (missing) & 0.00 & 0.01 & 0.05 & 0.00 & 0.00 & 0.05 \\
\hline Full-time nurses & 539.33 & 717.86 & $0.31^{* * *}$ & 798.56 & 1001.79 & $0.26^{* * *}$ \\
\hline Full-time nurses (missing) & 0.01 & 0.01 & 0.00 & 0.01 & 0.01 & -0.03 \\
\hline Total surgical volume & 456.74 & 572.67 & $0.21^{* * *}$ & 68.96 & 63.87 & $-0.07^{*}$ \\
\hline
\end{tabular}

\section{A matching-design approach to preference-based IV}

\subsection{Embedding observational IV data into a cluster-randomized experiment}

Consider analyzing data at the hospital level. Ideally, we would like to pair two hospitals with identical patient-level and hospital-level confounding variables, but different preference for using TEE during CABG surgery. For instance, we would like to pair two hospitals, HA and HB, if HA and HB have exactly the same number of patients and identical composition of patients, e.g., each with two White males in their $80^{\prime} s$ with three kinds of underlying comorbid conditions, etc. The hospital with a larger IV (hospital-level preference for TEE) will be considered the "encouraged" hospital and the other the "control" hospital.

However, such a strategy is very difficult if not impossible to implement. Instead, we consider the following assumption as described in (Zhang et al., 2020): hospitals' (or surgeons') preference is effectively randomized conditional on cluster-level covariates and some aggregate measures (e.g., mean and quantiles) of unit-level covariates within the cluster. In other words, the assumption says that it suffices to pair two hospitals (or surgeons) with the same (or at least very similar) average patient age, percentage of male patients, percentage of each important comorbid condition, etc, and cluster-level confounding variables like total number of hospital beds, total number of registered nurses, etc.

In practice, matching two hospitals (or surgeons) with identical percentage of male patients and identical percentage of each comorbidity is still very difficult. Instead in practice, researchers typically aim to create matched pairs in such a way that the mean values of each covariate in two groups after matching, i.e., the "encouraged" group and the "control" group, are as similar as possible. This is known as the covariate balance and can be assessed after each attempt to produce a match, without looking at the outcome data at all. We will regard a match as acceptable only if the standardized 
medRxiv preprint doi: https://doi.org/10.1101/2020.05.23.20110528; this version posted May 26,2020 . The copyright holder for this preprint (which was not certified by peer review) is the author/funder, who has granted medRxiv a license to display the preprint in perpetuity.

All rights reserved. No reuse allowed without permission.

differences of all covariates are less than 0.1. We will also test if there is a statistically significant difference for each covariate in two groups after matching using a two-sample t-test. We will report the p-values and ideally only approximately 1 out of 20 p-values should be smaller than 0.05 . If it turns out to be impossible to achieve this described covariate balance, we give priority to creating two well-comparable groups, possibly by discarding certain clusters, in order to ensure the internal validity of the study. When multiple matches could satisfy the desired covariate balance criteria, the match with a larger difference in the IV is preferred.

One way to achieve good covariate balance while maximizing the difference in the preference-based IV is to minimizing the robust Mahalanobis distance while penalizing two hospitals (or surgeons) having a similar preference using a technique called non-bipartite matching (Lu et al., 2011), also known as the near-far matching in the IV context (Baiocchi et al., 2010, Baiocchi et al., 2012, Neuman et al., 2014). In practice, penalties are also added to certain covariates to enforce better balance on these covariates.

\subsection{Dealing with missing data}

When merging the patient-level Medicare and Medicaid claims data with the cluster-level American Hospital Association data, we sometimes encounter missing data. This happens when we cannot identify certain patients' hospital and when AHA data contains missing data on cluster-level covariates for certain hospitals. We will deal with missing data by creating one "missing data indicator" covariate for each covariate with missing data, and balance these missing data indicators in the encouraged and control groups.

\subsection{Software}

We will be performing the described statistical matching using the $\mathrm{R}$ package nbpMatching (Lu et al., 2011, Beck et al., 2016) and summarizing the covariate balancing using the R package RItools (Hansen and Bowers, 2008, Bowers et al., 2019).

\section{$7 \quad$ Inference}

Suppose that there are $K$ matched pairs of two clusters (hospitals or surgeons). Suppose that cluster $j$ in matched pair $i$ contains $n_{k j}$ units (i.e., patients). Let $\widetilde{Z}_{k j}$ denote the observed IV of cluster $k$ in matched pair $j, k=1, \ldots, K$ and $j=1,2$. For each $k$, let $\bar{z}_{k}=\max \left\{\widetilde{Z}_{k 1}, \widetilde{Z}_{k 2}\right\}$ denote the observed IV for the encouraged cluster in matched pair $k$, and $\underline{z}_{k}=\min \left\{\widetilde{Z}_{k 1}, \widetilde{Z}_{k 2}\right\}$ for the control cluster in matched pair $k$. Let $d_{k j i}^{Z}$ and $r_{k j i}^{Z}$ denote the potential treatment indicator (using TEE or not) and the potential outcome that we want to study (e.g., can be either the primary or secondary outcome) of unit $i$ in cluster $j$ in matched pair $k$ given that the unit's IV score is $Z$ respectively, where $k=1, \ldots, K, j=1,2$, and $i=1 \ldots, n_{k j}$. Let $D_{k j i}$ and $R_{k j i}$ denote the observed treatment indicator and the observed outcome of unit $i$ in cluster $j$ in matched pair $k$ respectively, where $k=1, \ldots, K$, $j=1,2$, and $i=1 \ldots, n_{k j}$. Following Small et al. [2008] and Zhang et al. [2020], we consider the following cluster-level proportional treatment effect model:

$$
n_{k j}^{-1} \sum_{i=1}^{n_{k j}} r_{k j i}^{Z=\bar{z}_{k}}-n_{k j}^{-1} \sum_{i=1}^{n_{k j}} r_{k j i}^{Z=\underline{z}_{k}}=\beta\left(n_{k j}^{-1} \sum_{i=1}^{n_{k j}} d_{k j i}^{Z=\bar{z}_{k}}-n_{k j}^{-1} \sum_{i=1}^{n_{k j}} d_{k j i}^{Z=\underline{z}_{k}}\right) \quad \text { for some constant } \beta .
$$

We focus on testing $H_{0}^{\beta_{0}}: \beta=\beta_{0}$ versus $H_{1}^{\beta_{0}}: \beta \neq \beta_{0}$ for various $\beta_{0}$ (perhaps focusing on $\beta_{0}=0$ ) and build a two-sided $95 \%$ confidence interval for $\beta$. We will test $H_{0}^{\beta_{0}}$ versus $H_{1}^{\beta_{0}}$ by using the senm command in R package sensitivitymult (Rosenbaum, 2017), which performs the paired Huber's $\mathrm{M}$ test in a randomization inference (Rosenbaum, 2007), with the input vector of responses $y=$ $\left(n_{11}^{-1} \sum_{i=1}^{n_{11}} R_{11 i}-\beta_{0} \cdot n_{11}^{-1} \sum_{i=1}^{n_{11}} D_{11 i}, \ldots, n_{K 2}^{-1} \sum_{i=1}^{n_{K 2}} R_{K 2 i}-\beta_{0} \cdot n_{K 2}^{-1} \sum_{i=1}^{n_{K 2}} D_{K 2 i}\right)$. When using the senm command, we set all parameters to their default values (i.e., gamma $=1$, inner $=0$, trim $=3$, lambda $=$ $1 / 2, \operatorname{tau}=0$, alternative $=$ "greater", TonT $=$ FALSE), and get the corresponding deviate. We then take the square of the output deviate and then get the two-sided p-value by comparing the squared deviate 
medRxiv preprint doi: https://doi.org/10.1101/2020.05.23.20110528; this version posted May 26,2020 . The copyright holder for this preprint (which was not certified by peer review) is the author/funder, who has granted medRxiv a license to display the preprint in perpetuity.

All rights reserved. No reuse allowed without permission.

with the quantile function of the chi-square distribution with one degree of freedom. We will report a two-sided $p$-value using the above procedure for the null hypothesis $H_{0}: \beta=0$ versus $H_{1}: \beta \neq 0$ (i.e., $H_{0}^{\beta_{0}=0}$ versus $H_{1}^{\beta_{0}=0}$ ). We will also report a $95 \%$ confidence interval for $\beta$ (found by inverting the hypothesis test for $H_{0}^{\beta_{0}}$ under various $\beta_{0}$ using the above procedure; see Rosenbaum, 2002). We conduct this statistical analysis procedure for all the primary and secondary outcomes.

\section{Sensitivity analysis}

We follow the framework in Rosenbaum [1989] to conduct a sensitivity analysis for the conclusion drawn from the primary analysis. To be specific, we assume that IV dose assignment probability within the $k$-th matched pair can be biased by

$$
\frac{1}{1+\exp \left(\gamma \cdot\left(\bar{z}_{k}-\underline{z}_{k}\right)\right)} \leq \operatorname{pr}\left(\widetilde{Z}_{k 1}=\bar{z}_{k}, \widetilde{Z}_{k 2}=\underline{z}_{k}\right) \leq \frac{\exp \left(\gamma \cdot\left(\bar{z}_{k}-\underline{z}_{k}\right)\right)}{1+\exp \left(\gamma \cdot\left(\bar{z}_{k}-\underline{z}_{k}\right)\right)} \quad \text { for some } \gamma \geq 0
$$

To conduct a two-sided $\alpha$-level sensitivity analysis, we follow the procedure described in Rosenbaum [1989] to perform two one-sided $\alpha / 2$ sensitivity analyses for testing $H_{0}: \beta=0$ with the paired Huber's $\mathrm{M}$ test statistic used in Section 7 under the constraint (1) and various sensitivity parameters $\gamma$. For each $\gamma \geq 0$, we reject the null hypothesis of no treatment effect $H_{0}: \beta=0$ if and only if we reject $H_{0}: \beta=0$ in either one of the two one-sided $\alpha / 2$-level sensitivity analyses under the sensitivity parameter $\gamma$, forming a two-sided $\alpha$-level sensitivity analysis. We gradually increase $\gamma$ until we fail to reject and denote such changepoint $\gamma$ as $\widetilde{\gamma}$. We then report the average magnitude of the biased ratios of the odds of receiving encouragement among the $K$ matched pairs (i.e., $K^{-1} \sum_{k=1}^{K} \exp \left(\gamma \cdot\left(\bar{z}_{k}-\underline{z}_{k}\right)\right)$ ) to alter the conclusion drawn from the primary analysis under level $\alpha=0.05$.

\section{Match Results}

\subsection{Hospital-level match}

Table 2 summarizes a hospital-level match that meets the prespecified covariate balance criteria. There are a total of 1,215 hospitals that have performed at least one CABG surgery subject to the eligibility and exclusion criteria described in Section 3. We formed 484 matched pairs of 2 hospitals using 968 out of 1,215 hospitals $(79.7 \%)$ without ties on the IV. These 968 hospitals contain a total of 91,516 patients, accounting for $79.7 \%$ of all patients in our study population. Table 2 suggests that we have achieved very good covariate balance, with all standardized differences less than 0.1 . We also perform a simple two-sample t-test for each confounding variable and no confounding variable is significant at 0.1 level. For a graphical contrast of before and after matching covariate balance, see Figure $2 \mathrm{a}$. Moreover, hospitals' preference in the encouraged group is still remarkably different from that in the control group (0.37 vs. 0.72).

\section{$9.2 \quad$ Surgeon-level match}

Similarly, at the surgeon level, we are able to identify a total of 5,012 surgeons who have performed at least one CABG surgery on our study cohort. We are able to form 2,113 pairs of two surgeons using 4, 226 out of all 5, 012 (84.3\%) surgeons without ties on the IV. These 4, 226 surgeons represent a total of 95,275 patients, accounting for $93.8 \%$ of the total study cohort available at the surgeon level. Table 3 summarizes the covariate balance and Figure $2 \mathrm{~b}$ gives a graphical representation. Again, the covariate balance is stellar: all standardized differences are well below 0.1 and no covariate is statistically different at 0.05 level.

\subsection{Deciding a data granularity for primary analysis}

Both the hospital-level and the surgeon-level matches have achieved good balance, and the difference in the IV dosage is similar. Although we have paired two surgeons who have very similar cardiac surgical volume and work in very similar hospitals, there might still remain some residual confounding 
medRxiv preprint doi: https://doi.org/10.1101/2020.05.23.20110528; this version posted May 26, 2020. The copyright holder for this preprint (which was not certified by peer review) is the author/funder, who has granted medRxiv a license to display the preprint in perpetuity.

All rights reserved. No reuse allowed without permission.

Table 2: Covariate balance at hospital level before and after matching. Before matching: these three columns are duplicated from Table 1 and included here for convenience of comparison. After matching: 484 pairs of 2 hospitals are formed after matching. These 968 hospitals represent a total of 91,516 patients. Matching helps largely improve the covariate balance for a few key variables (highlighted). After matching, no covariate is statistically different in two groups at 0.1 level. Significance codes: "** $0.05 ;$ “**” $0.01 ; " * * *$; 0.001 .

\begin{tabular}{|c|c|c|c|c|c|c|}
\hline & \multicolumn{3}{|c|}{ Before Match } & \multicolumn{3}{|c|}{ After Match } \\
\hline & Below & Above & Absolute & Control & Encouraged & Absolute \\
\hline & Median & Median & Std. Diff. & Hospitals & Hospitals & Std. Diff. \\
\hline Hospital preference: proportion & 0.27 & 0.81 & 3.61 & 0.37 & 0.72 & 1.41 \\
\hline of TEE used in CABG surgeries & & & & & & \\
\hline \multicolumn{7}{|l|}{ Patient-level Characteristics } \\
\hline Average age & 75.10 & 75.33 & $0.13^{*}$ & 75.17 & 75.27 & 0.08 \\
\hline$\%$ male & 0.67 & 0.69 & $0.15 * *$ & 0.68 & 0.68 & 0.06 \\
\hline$\%$ white & 0.85 & 0.85 & 0.01 & 0.88 & 0.87 & 0.04 \\
\hline$\%$ elective & 0.46 & 0.47 & 0.06 & 0.48 & 0.48 & 0.00 \\
\hline$\%$ with arrhythmia & 0.10 & 0.11 & $0.13^{*}$ & 0.10 & 0.11 & 0.06 \\
\hline$\%$ with congestive heart failure & 0.11 & 0.11 & 0.08 & 0.10 & 0.10 & 0.03 \\
\hline$\%$ with diabetes & 0.16 & 0.16 & 0.03 & 0.15 & 0.15 & 0.04 \\
\hline$\%$ with hypertension & 0.27 & 0.28 & 0.07 & 0.27 & 0.27 & 0.02 \\
\hline$\%$ with obesity & 0.05 & 0.06 & 0.06 & 0.05 & 0.05 & 0.04 \\
\hline$\%$ with pulmonary diseases & 0.02 & 0.02 & $0.11^{*}$ & 0.02 & 0.02 & 0.01 \\
\hline$\%$ with renal diseases & 0.08 & 0.09 & 0.07 & 0.08 & 0.08 & 0.01 \\
\hline \multicolumn{7}{|l|}{ Cluster-level Characteristics } \\
\hline Hospital beds & 340.79 & 415.81 & $0.30 * * *$ & 351.82 & 357.64 & 0.03 \\
\hline Hospital beds (missing) & 0.01 & 0.01 & 0.00 & 0.01 & 0.00 & 0.05 \\
\hline Cardiac ICU (yes/no) & 0.71 & 0.72 & 0.03 & 0.71 & 0.71 & 0.02 \\
\hline Cardiac ICU (missing) & 0.07 & 0.09 & 0.06 & 0.08 & 0.08 & 0.02 \\
\hline Teaching hospital & 0.15 & 0.20 & $0.12^{*}$ & 0.13 & 0.12 & 0.01 \\
\hline Teaching hospital (missing) & 0.00 & 0.01 & 0.05 & 0.00 & 0.00 & 0.09 \\
\hline Full-time nurses & 539.33 & 717.86 & $0.31 * * *$ & 561.07 & 580.83 & 0.04 \\
\hline Full-time nurses (missing) & 0.01 & 0.01 & 0.00 & 0.01 & 0.00 & 0.05 \\
\hline Total surgical volume & 456.74 & 572.67 & $0.21 * * *$ & 487.72 & 491.02 & 0.01 \\
\hline
\end{tabular}

that biases surgeons' preference and affect the clinical outcomes, e.g., surgeons' education. Therefore, we choose to analyze the data at the hospital level with the hospital-level match, and leave the surgeon-level analysis to the sensitivity analysis.

\section{Sensitivity analyses}

We will analyze the data at the surgeon level using the surgeon-level match as a sensitivity analysis. 
Table 3: Covariate balance at surgeon level before and after matching. Before matching: these three columns are duplicated from Table 1 and included here for convenience of comparison. After matching: 2113 pairs of 2 surgeons are formed after matching. These 4,226 hospitals represent a total of 95, 275 patients. Matching helps largely improve the covariate balance for a few key variables (highlighted). After matching, no covariate is statistically different in two groups at 0.05 level. Significance codes: “*” 0.05 ; “*** 0.01 ; “***" 0.001 .

\begin{tabular}{|c|c|c|c|c|c|c|}
\hline & \multicolumn{3}{|c|}{ Before Match } & \multicolumn{3}{|c|}{ After Match } \\
\hline & Below & Above & Absolute & Control & Encouraged & Absolute \\
\hline & Median & Median & Std. Diff. & Hospitals & Hospitals & Std. Diff. \\
\hline $\begin{array}{l}\text { Surgeon preference: proportion } \\
\text { of TEE used in CABG surgeries }\end{array}$ & 0.39 & 0.95 & 3.09 & 0.44 & 0.85 & 1.50 \\
\hline \multicolumn{7}{|l|}{ Patient-level Characteristics } \\
\hline Average age & 75.25 & 75.53 & $0.10^{* * *}$ & 75.28 & 75.43 & 0.06 \\
\hline$\%$ male & 0.68 & 0.70 & $0.12 * * *$ & 0.68 & 0.69 & 0.04 \\
\hline$\%$ white & 0.88 & 0.86 & $0.11 * * *$ & 0.88 & 0.88 & 0.03 \\
\hline$\%$ elective & 0.48 & 0.47 & 0.01 & 0.47 & 0.47 & 0.01 \\
\hline$\%$ with arrhythmia & 0.11 & 0.12 & $0.06^{*}$ & 0.11 & 0.11 & 0.00 \\
\hline$\%$ with congestive heart failure & 0.10 & 0.12 & $0.13 * * *$ & 0.10 & 0.10 & 0.05 \\
\hline$\%$ with diabetes & 0.16 & 0.16 & 0.03 & 0.15 & 0.15 & 0.01 \\
\hline$\%$ with hypertension & 0.28 & 0.30 & $0.06^{*}$ & 0.28 & 0.28 & 0.00 \\
\hline$\%$ with obesity & 0.06 & 0.06 & 0.05 & 0.05 & 0.06 & 0.02 \\
\hline$\%$ with pulmonary diseases & 0.02 & 0.02 & $0.06^{*}$ & 0.02 & 0.02 & 0.01 \\
\hline$\%$ with renal diseases & 0.08 & 0.10 & $0.08^{* *}$ & 0.08 & 0.08 & 0.02 \\
\hline \multicolumn{7}{|l|}{ Cluster-level Characteristics } \\
\hline Hospital beds & 449.83 & 521.65 & $0.23 * * *$ & 450.34 & 453.68 & 0.01 \\
\hline Hospital beds (missing) & 0.01 & 0.01 & 0.03 & 0.01 & 0.01 & 0.01 \\
\hline Cardiac ICU (yes/no) & 0.83 & 0.83 & 0.00 & 0.83 & 0.83 & 0.01 \\
\hline Cardiac ICU (missing) & 0.04 & 0.05 & $0.07^{* *}$ & 0.04 & 0.05 & 0.02 \\
\hline Teaching hospital & 0.27 & 0.33 & $0.12^{* * *}$ & 0.26 & 0.25 & 0.03 \\
\hline Teaching hospital (missing) & 0.00 & 0.00 & 0.05 & 0.00 & 0.00 & 0.00 \\
\hline Full-time nurses & 798.56 & 1001.79 & $0.26 * * *$ & 800.23 & 812.10 & 0.02 \\
\hline Full-time nurses (missing) & 0.01 & 0.01 & 0.03 & 0.01 & 0.01 & 0.01 \\
\hline Total surgical volume & 68.96 & 63.87 & $0.07^{*}$ & 69.40 & 68.73 & 0.01 \\
\hline
\end{tabular}


medRxiv preprint doi: https://doi.org/10.1101/2020.05.23.20110528; this version posted May 26, 2020. The copyright holder for this preprint (which was not certified by peer review) is the author/funder, who has granted medRxiv a license to display the preprint in perpetuity.

All rights reserved. No reuse allowed without permission.

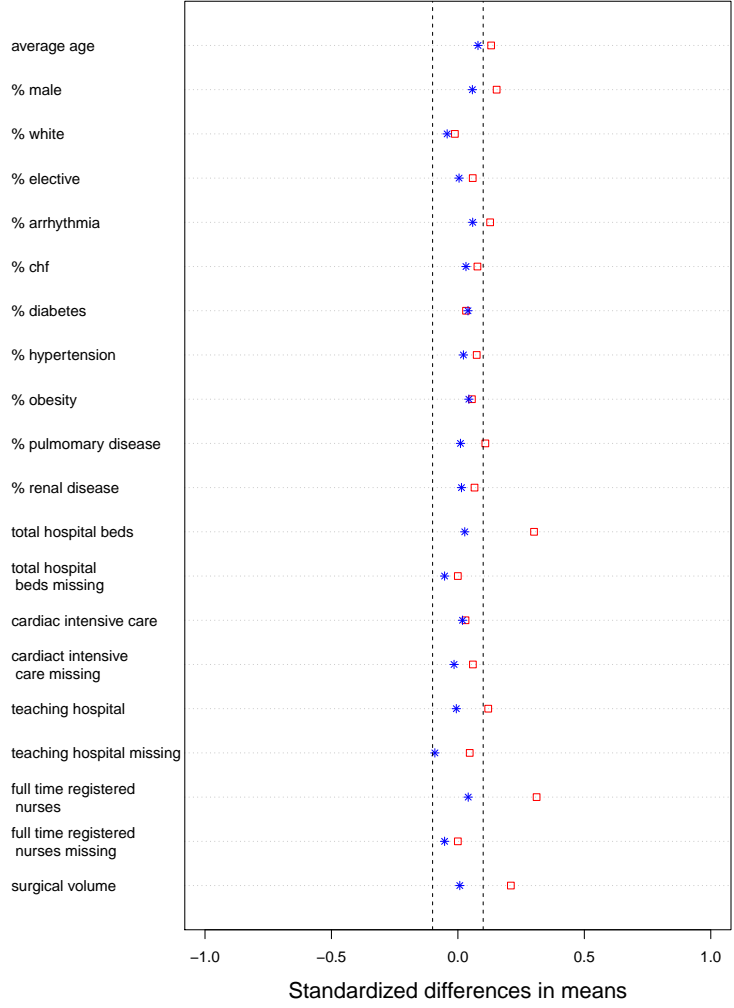

(a) Hospital level

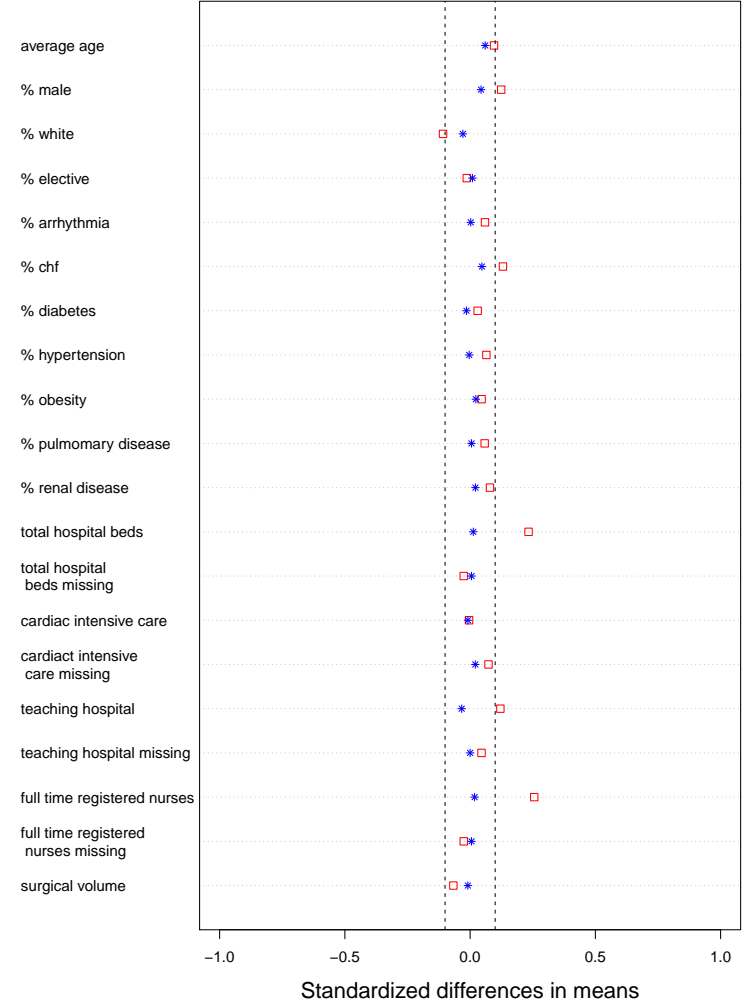

(b) Surgeon level

Figure 2: Love plot of standardized differences before (red squares) and after (blue asterisks) matching. Standardized difference before matching is calculated as (covariate mean of counties above the median preference for TEE - covariate mean of counties below the median preference for TEE) divided by the pooled within group standard deviation. Dashed lines are at -0.1 and 0.1 standardized differences. 
medRxiv preprint doi: https://doi.org/10.1101/2020.05.23.20110528; this version posted May 26, 2020. The copyright holder for this preprint (which was not certified by peer review) is the author/funder, who has granted medRxiv a license to display the preprint in perpetuity. All rights reserved. No reuse allowed without permission.

\section{References}

Michael A Acker, Michael K Parides, Louis P Perrault, Alan J Moskowitz, Annetine C Gelijns, Pierre Voisine, Peter K Smith, Judy W Hung, Eugene H Blackstone, John D Puskas, et al. Mitral-valve repair versus replacement for severe ischemic mitral regurgitation. N Engl J Med, 370:23-32, 2014.

Gabriel S Aldea, Nahush A Mokadam, Rayland Melford Jr, Douglas Stewart, Charles Maynard, Mark Reisman, and Richard Goss. Changing volumes, risk profiles, and outcomes of coronary artery bypass grafting and percutaneous coronary interventions. The Annals of thoracic surgery, 87(6): 1828-1838, 2009.

Gabriel S Aldea, Faisal G Bakaeen, Jay Pal, Stephen Fremes, Stuart J Head, Joseph Sabik, Todd Rosengart, A Pieter Kappetein, Vinod H Thourani, Scott Firestone, et al. The society of thoracic surgeons clinical practice guidelines on arterial conduits for coronary artery bypass grafting. The Annals of thoracic surgery, 101(2):801-809, 2016.

Mike Baiocchi, Dylan S Small, Scott Lorch, and Paul R Rosenbaum. Building a stronger instrument in an observational study of perinatal care for premature infants. Journal of the American Statistical Association, 105(492):1285-1296, 2010.

Mike Baiocchi, Dylan S Small, Lin Yang, Daniel Polsky, and Peter W Groeneveld. Near/far matching: a study design approach to instrumental variables. Health Services and Outcomes Research Methodology, 12(4):237-253, 2012.

Cole Beck, Bo Lu, and Robert Greevy. nbpMatching: Functions for Optimal Non-Bipartite Matching, 2016. URL https://CRAN.R-project.org/package=nbpMatching. R package version 1.5.1.

Jake Bowers, Mark Fredrickson, and Ben Hansen. RItools: Randomization Inference Tools, 2019. URL http://www.jakebowers.org/RItools.html. R package version 0.1-17.

M Alan Brookhart, Philip Wang, Daniel H Solomon, and Sebastian Schneeweiss. Evaluating short-term drug effects using a physician-specific prescribing preference as an instrumental variable. Epidemiology (Cambridge, Mass.), 17(3):268, 2006.

Christopher Cao, Con Manganas, Matthew Horton, Paul Bannon, Stine Munkholm-Larsen, Su C Ang, and Tristan D Yan. Angiographic outcomes of radial artery versus saphenous vein in coronary artery bypass graft surgery: a meta-analysis of randomized controlled trials. The Journal of thoracic and cardiovascular surgery, 146(2):255-261, 2013.

Cyril Charron, Vincent Caille, François Jardin, and Antoine Vieillard-Baron. Echocardiographic measurement of fluid responsiveness. Current opinion in critical care, 12(3):249-254, 2006.

Albert T Cheung, Joseph S Savino, Stuart J Weiss, Stanley J Aukburg, and Jesse A Berlin. Echocardiographic and hemodynamic indexes of left ventricular preload in patients with normal and abnormal ventricular function. Anesthesiology, 81(2):376-387, 1994.

Holger K Eltzschig, Peter Rosenberger, Michaela Löffler, John A Fox, Sary F Aranki, and Stanton K Shernan. Impact of intraoperative transesophageal echocardiography on surgical decisions in 12,566 patients undergoing cardiac surgery. The Annals of thoracic surgery, 85(3):845-852, 2008.

Andrew J Epstein, Daniel Polsky, Feifei Yang, Lin Yang, and Peter W Groeneveld. Coronary revascularization trends in the united states, 2001-2008. Jama, 305(17):1769-1776, 2011.

Constantine E Frangakis, Donald B Rubin, and Xiao-Hua Zhou. Clustered encouragement designs with individual noncompliance: Bayesian inference with randomization, and application to advance directive forms. Biostatistics, 3(2):147-164, 2002.

Laura Faden Garabedian, Paula Chu, Sengwee Toh, Alan M Zaslavsky, and Stephen B Soumerai. Potential bias of instrumental variable analyses for observational comparative effectiveness research. Annals of internal medicine, 161(2):131-138, 2014. 
medRxiv preprint doi: https://doi.org/10.1101/2020.05.23.20110528; this version posted May 26, 2020. The copyright holder for this preprint (which was not certified by peer review) is the author/funder, who has granted medRxiv a license to display the preprint in perpetuity. All rights reserved. No reuse allowed without permission.

Rebecca T Hahn, Theodore Abraham, Mark S Adams, Charles J Bruce, Kathryn E Glas, Roberto M Lang, Scott T Reeves, Jack S Shanewise, Samuel C Siu, William Stewart, et al. Guidelines for performing a comprehensive transesophageal echocardiographic examination: recommendations from the american society of echocardiography and the society of cardiovascular anesthesiologists. Journal of the American Society of Echocardiography, 26(9):921-964, 2013.

Ben B. Hansen and Jake Bowers. Covariate balance in simple, stratified and clustered comparative studies. Statistical Science, 23(2):219-236, 2008.

Miguel A Hernán and James M Robins. Instruments for causal inference: an epidemiologist's dream? Epidemiology, pages 360-372, 2006.

Jan N Hilberath, Daryl A Oakes, Stanton K Shernan, Bernard E Bulwer, Michael N D'Ambra, and Holger K Eltzschig. Safety of transesophageal echocardiography. Journal of the American Society of Echocardiography, 23(11):1115-1127, 2010.

L David Hillis, Peter K Smith, Jeffrey L Anderson, John A Bittl, Charles R Bridges, John G Byrne, Joaquin E Cigarroa, Verdi J DiSesa, Loren F Hiratzka, Adolph M Hutter, et al. 2011 accf/aha guideline for coronary artery bypass graft surgery: executive summary: a report of the american college of cardiology foundation/american heart association task force on practice guidelines developed in collaboration with the american association for thoracic surgery, society of cardiovascular anesthesiologists, and society of thoracic surgeons. Journal of the American College of Cardiology, 58(24):2584-2614, 2011.

Jeffrey P Jacobs, John E Mayer Jr, Sara K Pasquali, Kevin D Hill, David M Overman, James D St Louis, S Ram Kumar, Carl L Backer, Charles D Fraser, James S Tweddell, et al. The society of thoracic surgeons congenital heart surgery database: 2018 update on outcomes and quality. The Annals of thoracic surgery, 105(3):680-689, 2018.

Richard A Krasuski, Stephen A Hart, Drew Allen, Athar Qureshi, Gosta Pettersson, Penny L Houghtaling, Lillian H Batizy, and Eugene Blackstone. Prevalence and repair of intraoperatively diagnosed patent foramen ovale and association with perioperative outcomes and long-term survival. JAMA, 302(3):290-297, 2009.

Bo Lu, Robert Greevy, Xinyi Xu, and Cole Beck. Optimal nonbipartite matching and its statistical applications. The American Statistician, 65(1):21-30, 2011.

Emily J MacKay, Rachel M Werner, Peter W Groeneveld, Nimesh D Desai, Peter P Reese, Jacob T Gutsche, John G Augoustides, and Mark D Neuman. Transesophageal echocardiography, acute kidney injury, and length of hospitalization among adults undergoing coronary artery bypass graft surgery. Journal of cardiothoracic and vascular anesthesia, 34(3):687-695, 2020.

Nahush A Mokadam, Ryland E Melford, Jr, Charles Maynard, John R Goss, Douglas Stewart, Mark Reisman, and Gabriel S Aldea. Prevalence and procedural outcomes of percutaneous coronary intervention and coronary artery bypass grafting in patients with diabetes and multivessel coronary artery disease. Journal of cardiac surgery, 26(1):1-8, 2011.

Mark D Neuman, Paul R Rosenbaum, Justin M Ludwig, Jose R Zubizarreta, and Jeffrey H Silber. Anesthesia technique, mortality, and length of stay after hip fracture surgery. Jama, 311(24):25082517, 2014.

Rick A Nishimura, Catherine M Otto, Robert O Bonow, Blase A Carabello, John P Erwin, Robert A Guyton, Patrick T O'Gara, Carlos E Ruiz, Nikolaos J Skubas, Paul Sorajja, et al. 2014 aha/acc guideline for the management of patients with valvular heart disease: executive summary: a report of the american college of cardiology/american heart association task force on practice guidelines. Journal of the American College of Cardiology, 63(22):2438-2488, 2014. 
medRxiv preprint doi: https://doi.org/10.1101/2020.05.23.20110528; this version posted May 26, 2020. The copyright holder for this preprint (which was not certified by peer review) is the author/funder, who has granted medRxiv a license to display the preprint in perpetuity.

All rights reserved. No reuse allowed without permission.

Rick A Nishimura, Catherine M Otto, Robert O Bonow, Blase A Carabello, John P Erwin, Lee A Fleisher, Hani Jneid, Michael J Mack, Christopher J McLeod, Patrick T O'Gara, et al. 2017 aha/acc focused update of the 2014 aha/acc guideline for the management of patients with valvular heart disease: a report of the american college of cardiology/american heart association task force on clinical practice guidelines. Journal of the American College of Cardiology, 70(2):252-289, 2017.

Michael J Reardon, Nicolas M Van Mieghem, Jeffrey J Popma, Neal S Kleiman, Lars Søndergaard, Mubashir Mumtaz, David H Adams, G Michael Deeb, Brijeshwar Maini, Hemal Gada, et al. Surgical or transcatheter aortic-valve replacement in intermediate-risk patients. New England Journal of Medicine, 376(14):1321-1331, 2017.

Robert F Riley, Creighton W Don, Wayne Powell, Charles Maynard, and Larry S Dean. Trends in coronary revascularization in the united states from 2001 to 2009: recent declines in percutaneous coronary intervention volumes. Circulation: cardiovascular quality and outcomes, 4(2):193-197, 2011.

Paul R Rosenbaum. Sensitivity analysis for matched observational studies with many ordered treatments. Scandinavian Journal of Statistics, pages 227-236, 1989.

Paul R Rosenbaum. Observational Studies. Springer, 2002.

Paul R Rosenbaum. Sensitivity analysis for m-estimates, tests, and confidence intervals in matched observational studies. Biometrics, 63(2):456-464, 2007.

Paul R. Rosenbaum. sensitivitymult: Sensitivity Analysis for Observational Studies with Multiple Outcomes, 2017. URL https://CRAN.R-project.org/package=sensitivitymult. R package version 1.0.2.

Yaron Shapira, Mordehay Vaturi, Daniel E Weisenberg, Ehud Raanani, Gideon Sahar, Eitan Snir, Alexander Battler, Bernardo A Vidne, and Alex Sagie. Impact of intraoperative transesophageal echocardiography in patients undergoing valve replacement. The Annals of thoracic surgery, 78(2): 579-583, 2004.

Yaron Shapira, Daniel E Weisenberg, Mordehay Vaturi, Erez Sharoni, Ehud Raanani, Gideon Sahar, Bernardo A Vidne, Alexander Battler, and Alex Sagie. The impact of intraoperative transesophageal echocardiography in infective endocarditis. IMAJ-RAMAT GAN-, 9(4):299, 2007.

Fernanda Silva, Ricardo Arruda, Angelo Nobre, Mario Mendes, Alberto Lemos, Javier Gallego, Samuel Mendes, and Joao Cravino. Impact of intraoperative transesophageal echocardiography in cardiac surgery: retrospective analysis of a series of 850 examinations. Revista portuguesa de cardiologia: orgao oficial da Sociedade Portuguesa de Cardiologia= Portuguese journal of cardiology: an official journal of the Portuguese Society of Cardiology, 29(9):1363-1382, 2010.

Dylan S Small, Thomas R Ten Have, and Paul R Rosenbaum. Randomization inference in a grouprandomized trial of treatments for depression: covariate adjustment, noncompliance, and quantile effects. Journal of the American Statistical Association, 103(481):271-279, 2008.

Craig R Smith, Martin B Leon, Michael J Mack, D Craig Miller, Jeffrey W Moses, Lars G Svensson, E Murat Tuzcu, John G Webb, Gregory P Fontana, Raj R Makkar, et al. Transcatheter versus surgical aortic-valve replacement in high-risk patients. New England Journal of Medicine, 364(23): 2187-2198, 2011.

The Society of Thoracic Surgeons. The sts adult cardiac surgery database (acsd), 2016a.

The Society of Thoracic Surgeons. The sts adult cardiac surgery database (acsd), 2016b.

Bo Zhang, Siyu Heng, Emily MacKay, and Ting Ye. A matching-based approach to clustered encouragement designs with individual noncompliance with application to physician-preference-based ivs. unpublished, 2020. 